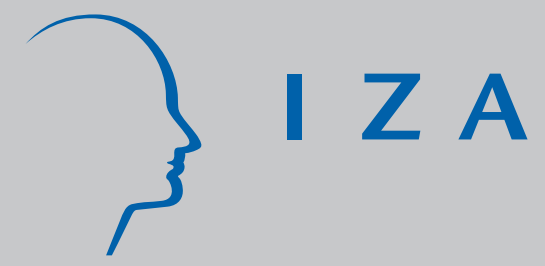

IZA DP No. 8747

On the Economic Geography of International Migration

Çağlar Özden

Christopher Parsons

December 2014

Forschungsinstitut zur Zukunft der Arbeit Institute for the Study of Labor 


\title{
On the Economic Geography of International Migration
}

\author{
Çağlar Özden \\ World Bank and IZA \\ Christopher Parsons \\ University of Oxford

\section{Discussion Paper No. 8747 \\ December 2014}

\author{
IZA \\ P.O. Box 7240 \\ 53072 Bonn \\ Germany \\ Phone: +49-228-3894-0 \\ Fax: +49-228-3894-180 \\ E-mail: iza@iza.org
}

Any opinions expressed here are those of the author(s) and not those of IZA. Research published in this series may include views on policy, but the institute itself takes no institutional policy positions. The IZA research network is committed to the IZA Guiding Principles of Research Integrity.

The Institute for the Study of Labor (IZA) in Bonn is a local and virtual international research center and a place of communication between science, politics and business. IZA is an independent nonprofit organization supported by Deutsche Post Foundation. The center is associated with the University of Bonn and offers a stimulating research environment through its international network, workshops and conferences, data service, project support, research visits and doctoral program. IZA engages in (i) original and internationally competitive research in all fields of labor economics, (ii) development of policy concepts, and (iii) dissemination of research results and concepts to the interested public.

IZA Discussion Papers often represent preliminary work and are circulated to encourage discussion. Citation of such a paper should account for its provisional character. A revised version may be available directly from the author. 


\begin{abstract}
On the Economic Geography of International Migration*

We exploit the bilateral and skill dimensions from recent data sets of international migration to test for the existence of Zipf's and Gibrat's Laws in the context of aggregate and highskilled international immigration and emigration using graphical, parametric and nonparametric analysis. The top tails of the distributions of aggregate and high-skilled immigrants and emigrants adhere to a Pareto distribution with an exponent of unity i.e. Zipf's Law holds. We find some evidence in favour of Gibrat's Law holding for immigration stocks, i.e. that the growth in stocks is independent of their initial values and stronger evidence that immigration densities are diverging over time. Conversely, emigrant stocks are converging in the sense that countries with smaller emigrant stocks are growing faster than their larger sovereign counterparts. Lastly, high skilled immigration and emigration stocks expressed in levels or as densities all exhibit signs of convergence. We conclude by discussing some competing mechanisms that could be driving the observed patterns including: differing fertility rates, reductions in emigration restrictions, migrant sorting and selective immigration policies, immigrant networks and persisting wage differentials.
\end{abstract}

JEL Classification: F22, J61, O15

Keywords: Zipf's Law, Gibrat's Law, international migration

Corresponding author:

Çağlar Özden

Development Research Group

The World Bank

Mail Stop MC3-303

1818 H Street, NW

Washington, DC 20433

USA

E-mail: cozden@worldbank.org

\footnotetext{
* We are grateful to Hillel Rapoport, Ferdinand Rauch and an anonymous referee for useful and timely comments and would like to extend our gratitude to Simone Bertoli and Frédéric Docquier for their combined encouragement for writing this paper. This paper benefited from the financial support of the FERDI (Fondation pour les Etudes et Recherches sur le Développement International) and of the program "Investissements d'Avenir" (ANR-10-LABX-14-01) of the French government.
} 


\section{Introduction}

In urban economics, Zipf's Law and Gibrat's Law help describe the relationships between cities' relative population sizes and growth rates. In this paper, we link the international migration and urban economics literatures and examine the existence of Gibrat's and Zipf's Laws in immigration and emigration levels and densities, ${ }^{1}$ drawing upon two of the most recent bilateral migration databases, Özden et al. (2011) and Artuç et al. (2014).

Zipf's law for cities states that the size distribution of cities within a country can be approximated by a power law distribution with a parameter of one. ${ }^{2}$ Thus, if cities are ranked according to size, the $n$th largest city would be $1 / n$ of the size of the largest city. Alternatively, a regression with $\ln ($ city size rank) as the dependent variable and $\ln ($ city size $)$ as the main explanatory variable can be used to identify this regularity. The coefficient is estimated to be 1 with a high level of precision across various samples and time periods, especially when larger cities are considered.

Gibrat's law rather concerns growth rates and was initially identified in the context of French firms (Gibrat, 1931). When applied to cities, it states that different cities' growth rates have a common mean and are independent of initial size. While the analysis developed separately, the seminal paper of Gabaix (1999) establishes the crucial link between the two laws: when cities grow according to Gibrat's law, their size distribution will follow Zipf's law in steady state. This, together with numerous results from the urban economics literature, provide further discussion on the validity of Gibrat's Law, which instead predicts that the resulting distribution is log-normal. Eeckhout (2004) accommodates both 'laws' by showing that a Pareto distribution best fits the observed pattern if only the upper tail of the distribution of city sizes is considered. Conversely, a log-normal distribution is most suited to describe the entire distribution. These patterns

\footnotetext{
${ }^{1}$ Throughout this paper, total immigrant densities are defined as the number of immigrants divided by the number of immigrants and the population at destination and similarly total emigrant densities as a country's total emigration stock divided by the total number of emigrants and the domestic population at origin, to ensure that these measures are bounded between zero and one. Contrastingly, our high-skilled measures are instead calculated as the share of high skilled immigrants or emigrants in the total immigrant or emigrant stock, respectively.

${ }^{2}$ A power law is a distribution function of the type $P($ size $>S)=a / S^{\theta}$ for large $S$. Zipf's law states that $\theta=1$.
} 
are observed across many countries and are discussed in detail in Gabaix and Ioannides (2004).

Relatively few studies conduct similar analyses to compare country sizes since the theoretical models used to explain Zipf's and Gibrat's laws are not truly applicable when the unit of observation is a sovereign nation. Governments exercise considerable control over their international (as opposed to internal) borders and can dictate who can enter and, to a certain extent, exit. Geographical and cultural barriers impose additional constraints on international migration and country size. The most prominent study is Rose (2005) who uses countries as the relevant geographical entities. He concludes that the 'hypothesis of no effect of size on growth usually cannot be rejected'. ${ }^{3}$ When testing for Zipf's law for countries, Rose (2005) shows that it also strongly holds in the upper tail of the distribution of country sizes. The only study examining Gibrat's and Zipf's laws in international immigration is Clemente et al. (2011). In the context of immigrant levels and densities, they find Zipf's law only holds for immigrant levels for the top 50 countries.

Zipf's law implies a concentrated distribution of the total population among a few large cities. We observe similar patterns in international migration although the raw data demonstrate a discernable shift over time in emigration patterns. In 2000, the top ten destination countries accounted for around $57 \%$ of the world migrant stock, which is approximately equivalent to the total emigrant stocks of the top 25 emigration countries. While immigrant concentrations remained stable in terms of destination countries over time, the same is not true for origin countries since in 1960, the top ten destination countries received $54 \%$ of all migrants, equivalent to the total emigrant stocks of just 9 origin countries. These basic numbers suggest an agglomeration of migration in the upper tail of the distribution as shown in the top-left panel of Figure 1.

Figure 2 rather plots the growth in bilateral migration corridors over the period

\footnotetext{
${ }^{3}$ Offering a critique of Rose (2005), González-Val and Sanso-Navarro (2010) examine Gibrat's Law in the context of countries using a variety of empirical techniques, both parametric (panel unit root testing) and non-parametric (kernel regressions and transition matrices). Since these authors find much weaker evidence of the existence of Gibrat's Law they conclude that "the theoretical modelling of country population in accordance with Gibrats Law should not concern us so much until stronger evidence for it is found."
} 
1960-2000 against their initial values, a graphical examination of whether Gibrat's Law holds. The two lines correspond to lines of best fits should zero values be included or excluded. When included, by adding one to the log, the figure suggests that Gibrat's Law holds. When excluded, signs of convergence across the entire distribution of bilateral migration corridors are evident. This difference is indicative of non-linearities in the sample with positive values, which therefore warrants further examination.

Motivated by these stylized facts, we draw upon two recent bilateral migration databases, Özden et al. (2011) and Artuç et al. (2014) to examine Zipf's and Gibrat's Laws in the context of international migration. These yield two advantages. First, global bilateral migration data allow us to calculate origin countries' emigrant stocks, as opposed to simply immigrant stocks in destination countries. Secondly, the latter database, which reports bilateral migration stocks by education levels, allows us to further delineate migrants' education levels. By delving deeper into these observed patterns of international migration over the period 1960-2000, through examining the existence of Zipf's and Gibrat's Laws, we can analyze to what extent the underlying trends in global migration patterns are converging or diverging.

We find that Zipf's Law holds in the upper tails of the distributions for both immigration and emigration levels for all time periods, particularly strongly in the case of immigration. The results are less precise in terms of high skilled immigrant and emigrant levels, although we cannot reject the coefficient being equal to one. With respect to Gibrat's law, our results are somewhat less uniform. Our parametric analysis provides evidence of convergence since growth rates between 1960 and 2000 are negatively correlated with initial levels of aggregate and high-skilled immigration and emigration in both levels and densities. In our non-parametric analysis, we find some evidence in favour of Gibrat's Law holding for immigration stocks, i.e. that the growth in stocks is independent of their initial values and stronger evidence that immigration densities are diverging over time. Conversely, emigrant stocks are converging in the sense that countries with smaller emigrant stocks are growing faster than their larger sovereign counterparts. In terms of high-skilled migration, this subsequent analysis provides evidence that high-skilled immigration and emigration levels and densities are all converging over time. 
In the context of cities, the urban economics literature has devoted considerable attention to identify various economic mechanisms that might explain the patterns behind Gibrat's and Zipf's laws (see Gabaix and Ioannides (2004)). These include agglomeration and congestion externalities, transport costs and presence of natural resources. For example, Gabaix (1999) links Gibrat's and Zipf's laws through internal migration due to "amenity shocks." Such explanations on the spatial allocation of economic activity and population movements potentially also apply to international migration. The key difference, as previously mentioned, is the additional, and at times restrictive, legal, geographic and cultural barriers that constrain international migration flows.

The natural question is which economic and social forces underpin the findings from our exploration of the two laws. Based on the theoretical work in the literature to date and by examining which countries constitute various parts of the distributions in question, we detail a number of competing mechanisms that could produce the observed patterns in our results. These include differing fertility rates, reductions in emigration restrictions, migrant sorting and selective immigration policies, immigrant networks and persisting wage differentials.

The following Section presents a few stylized facts about the agglomeration observed in international migration, which provides motivation for Section 3, our analysis of Zipf's Law. In Section 4, we analyse the extent to which the underlying distributions of our variables of interest approximate to log-normal distributions. Section 5 presents an examination of Gibrat's Law in international migration patterns, while Section 6 provides plausible explanations for our results. Finally we conclude.

\section{The Agglomeration of International Migration}

This section details the observed agglomeration in global migration patterns. Özden et al. (2011) show that while the global migrant stock increased from 92 million to 165 million between 1960 and $2000,{ }^{4}$ immigrants as a share of the world population actually decreased

\footnotetext{
${ }^{4}$ The data from the 2010 census round is currently being collated since these data are typically published with a significant lag.
} 
from 3.05 percent to 2.71 percent. While South-South migration dominates the global migration patterns, mainly due to the millions of migrants created during the partition of India and the collapse of the Soviet Union, the most significant trend between 1960 and 2000 has been the surge in the economically motivated South-to-North migration.

Table 1 presents summary statistics of the frequency and the total numbers of migrants comprising bilateral migrant corridors of various sizes (zero corridors, 1-50 migrants, 51-500 migrants, 501-5,000 migrants, 5,001-50,000 migrants and corridors containing more than 50,000 migrants) over the period 1960-2000. Over time, the number of empty bilateral migrant corridors has fallen substantially as the global labor markets have become more interconnected. While smaller corridors are more common, these comprise far fewer international migrants as when compared to larger corridors. In 2000, around 41,000 bilateral corridors (out of 51,000 total corridors) contained fewer than 50 migrants each, accounting for only 0.1 percent of total global migrant stock. Conversely, in the same year, just 505 corridors accounted for over 80 percent of 160 million migrants across the world. The data for high-skilled migration demonstrate an even greater degree of agglomeration. According to Artuç et al. (2014), in both 1990 and 2000, the top ten destinations hosted no less than $74 \%$ of the world's high skilled migrants.

\section{Zipf's Law in International Migration}

This section examines the existence of Zipf's Law, the so-called rank-size rule, commonly observed in the upper tail of the distribution of various geographical entities. Typically the presence of Zipf's Law is analysed graphically and using regression techniques. ${ }^{5}$ Both approaches first rank the size (population) variable of interest $S$, from the largest to the smallest $\left(S_{1}>S_{2}>S_{3}>\ldots S_{N}\right)$. Then the natural logarithm of the rank variable is analysed with respect to the natural logarithm of the size (population) variable.

The top two panels in Figure 3 show the scatter plots of the natural logarithms of the rank of total immigrant and emigrant levels for the 50 countries in the top tail of the

\footnotetext{
${ }^{5}$ We do not report estimates using the Hill estimator since Gabaix and Ioannides (2004) argue that in finite samples the properties of this estimator are 'worrisome'.
} 
various distributions contained in Özden et al. (2011). Although we only plot these for the year 2000, these graphs are representative of other decades as well. The bottom two panels use the data from Artuç et al. (2014) and refer to high-skilled migrants, defined as having completed at least one year of tertiary education. Clear linear trends are evident, but the line imposed demonstrates that some deviations from Zipf's Law clearly exist. For a more detailed inquiry we turn to simple regression analysis. Zipf's Law can be expressed as:

$$
P(\text { Size }>S)=\alpha S^{(-\beta)}
$$

where $\alpha$ is a constant and $\beta=1$ if Zipf's law holds. For the basis of our regression analysis we denote $m$ to be the stock of immigrants or emigrants, expressed either in levels or in terms of densities, high-skilled or otherwise. Next, $r$ is the rank of $m$, when ordered from highest to lowest. Equation (1) expressed in logarithmic form can be written as:

$$
\log r=\alpha+\beta \log m+\epsilon
$$

where $\epsilon$ is an error term and $\beta$ is the Pareto exponent, which equals unity if Zipf's Law holds. Equation (2) is typically estimated using OLS, which leads to strongly biased results in small samples as shown by Gabaix and Ibragimov (2007) who derive the asymptotic expansions for the bias of $\beta$ in regression (2). These authors further argue that these biases are minimised when one half is subtracted from the rank. The regression to be estimated becomes:

$$
\log (r-0.5)=\alpha+\beta \log m+\epsilon
$$

Despite this adjustment, the standard error of $\beta$ is not equal to that obtained from OLS, but instead can be approximated as $\beta \sqrt{\frac{2}{n}}$ (Gabaix and Ioannides (2004), Gabaix and Ibragimov (2007)). Table 2 presents the regression results from across our various specifications together with corrected standard errors for each decade from 1960 to 2000.

Beginning with the total migrant measures, the Pareto coefficient is remarkably close to unity (at 1.03 for 2000) for the 50 largest countries in the upper tail of the immigrant 
size distribution. Although further from unity, we cannot reject that the Pareto coefficient is equal to 1 in the upper tail of the emigrant size distribution. Zipf's Law is resolutely rejected across the entirety of both size distributions however. This is consistent with the results presented in Eeckhout (2004) who argues that the Pareto distribution best describes the upper tail but a log-normal distribution provides a better fit over the entire distribution.

The estimates of the Zipf coefficient for immigrant and emigrant levels remained fairly stable over time, although the coefficient rose significantly in the upper tail of the emigrant size distribution, providing evidence of convergence over time. Similarly, the estimates on immigrant densities rose in the upper tail of the distribution, demonstrating some convergence across these countries, but fell across the entire distribution, i.e. providing evidence of divergence. The estimates on emigrant densities show some signs of convergence between 1960 and 2000 .

Turning to the High Skill migration numbers in the bottom eight rows of Table 2, although the point estimates on the Zipf coefficient are substantively different from unity, we cannot reject that the estimates are statistically different from 1. Both immigrant and emigrant levels are similar in both 1990 and 2000, if anything exhibiting marginal convergence. High skilled immigrant and emigrant densities both increased significantly across the entire distribution, which again is indicative of a process of convergence across the globe.

\section{An Examination of Log-Normality}

The previous section showed that we cannot reject the existence of Zipf's Law in the upper tails of the distributions of total and high skilled immigrants and emigrants in levels, although when the entire distribution is considered, we plainly reject Zipf's Law. With these results in hand, we next empirically test whether or not the underlying distributions of our variables approximate to log normal. If this is the case, it might be the case that Gibrat's law holds i.e. that these distributions could have resulted from an independent 
growth process.

Figures 1 and 4, show the (Epanechnikov) kernel density plots, in 1960 and 2000 for total emigrant levels and densities and total immigrant levels and densities and then similarly in 1990 and 2000 for the highly skilled. We implement a series of Kolmogorov-Smirnov equality-of-distributions tests where the null hypothesis is that the relevant variable is distributed log-normally. Table 3 presents the corrected p-values from the Kolmogorov-Smirnov tests for each migration variable in 1960 and 2000 and in 1990 and 2000 for the highly skilled. In just over half of the total cases, we fail to reject the null hypothesis of (log) normality. Cases where we can reject the null are highlighted in bold. Both immigrant levels and densities are log-normally distributed as was the case in Clemente et al. (2011). ${ }^{6}$ Since if Gibrat's Law were to hold, the resulting distributions of the relevant variables will be log-normal, we proceed by examining whether Gibrat's Law holds for our various measures of international migration.

\section{Gibrat's Law in International Migration}

As opposed to the static analysis presented when discussing Zipf's Law, an examination of Gibrat's Law with growth rates requires a dynamic analysis of global migration movements. Gibrat (1931) postulated that "The Law of proportionate effect will therefore imply that the logarithms will be distributed following the (normal distribution)" (as quoted in Eeckhout (2004)). In other words, should the growth of geographical entities be independent of their size, their growth will subsequently result in a log-normal distribution. Of course, this does not mean that a log-normal distribution implies that Gibrat's Law necessarily holds.

We estimate parametric and non-parametric kernel regressions to test for the existence of Gibrat's Law. These regress the size of migrant populations (in our case in levels and densities) on their growth. ${ }^{7}$ In logarithmic form, parametric regressions take the following

\footnotetext{
${ }^{6}$ Note that the scale of our density figures differ from Clemente et al. (2011) since we calculate our density measure differently and we further omit refugees, i.e. forced migrants from our analysis.

${ }^{7}$ While Panel Unit Root tests have been suggested as appropriate in the literature, it is not feasible
} 
form:

$$
\log m_{i t}-\log m_{i t-1}=\gamma+\delta \log m_{i t}+\mu_{i t}
$$

where $\gamma$ is a constant and $\mu$ is a stochastic error term, such that if $\delta=0$ then Gibrat's Law holds. Following the analysis of Eaton and Eckstein (1997), we distinguish between the aforementioned case of (i) parallel growth, when $\delta=0$, i.e. when growth does not depend on initial size, (ii) convergent growth, when $\delta<0$ when smaller initial populations grow faster than their larger counterparts so that there is long-run convergence to the median value and (iii) divergent growth when $\beta>0$, meaning that growth is a positive monotonic function of initial size. Evidence of either convergent or divergent growth can therefore be taken as evidence against the existence of Gibrat's Law.

Table 4 presents the results from this first round of analysis, where Equation (4) is estimated with OLS with robust standard errors, to insulate our results from heteroskedasticity which is commonplace in these types of regressions González-Val and Sanso-Navarro (2010). Although Gibrat's Law is fundamentally a long run concept, we estimate Equation (4) across each decade for each of our different measures of immigration and emigration.

The simplest and most intuitive way to test for the existence of Gibrat's Law is by plotting geographical entities' growth on their initial values, which for the sake of brevity are not included here but are available on request. Such an analysis is strongly reflected in the results in Table $4 .^{8}$ Across all decades and across all measures, the parametric regression results are negative and statistically significant or else statistically insignificant. These results are indicative of convergence over time or indeed of Gibrat's Law holding. Since Gibrat's Law is a long-run concept, the results from over the period 1960-2000 should be given more credence. In each case the results are strongly negative and statistically significant, providing some evidence of convergence in immigrant and emigrant levels and densities over time.

Our OLS estimates yield total or aggregate effects of initial size on subsequent growth,

to conduct such an analysis in the current work due to the frequency of our data (decennial) and the low number of observations in our underlying data (five points in time or four growth rates).

${ }^{8}$ We do not report the $R^{2}$ from these regressions although these are very low for our decadal regressions and substantially higher for those regressions run over forty years. 
while conversely non-parametric estimates facilitate an analysis of the effects of initial size across the entire distribution. We follow Eeckhout (2004) for our non-parametric analysis of Gibrat's Law and adopt the following specification:

$$
g_{i}=m\left(S_{i}\right)+\epsilon_{i}
$$

where $g_{i}$ is the decadal growth of one of our migration measures normalised between two consecutive periods by subtracting the mean growth and dividing through by the standard deviation. Maintaining our notation from earlier, $m_{i}$ is the corresponding logarithm of the relevant migration measure. Since such estimators are sensitive to atypical values, we follow Clemente et al. (2011) and drop the bottom 5\% of observations. Figures 5 and 6 plot the results from these regressions and we would expect these values to be flat and concentrated around zero if Gibrat's Law were to hold.

In keeping with the findings of Clemente et al. (2011), we find, at least across most of the distribution of the stock of immigrants, that Gibrat's Law holds. The major exceptions are those countries in the lower end of the distribution, which tend to grow faster than the other countries in the distribution. We find much stronger evidence of the divergence in immigrant densities across the globe. The underlying distributions for both of these variables are log-normal however, demonstrating that log-normality can result, despite Gibrat's Law not holding. Emigrant stocks exhibit strong signs of convergence with smaller emigrant stocks growing far more strongly than larger emigrant stocks. The results from the kernel regression for emigrant densities are mixed however, no doubt in part reflecting the role played by Small Island Developing States (see de la Croix et al. (2013)) as they tend to have relatively higher shares of emigration.

All of the kernel regression plots pertaining to the highly skilled, reflect patterns of convergence since they slope down from left to right. Our estimates for emigrant levels are never statistically different from zero, providing some evidence that Gibrat's Law holds in this context, although the confidence intervals are very wide. The same is true for the middle and the very upper tail of the distribution of high skilled immigrants in levels. 


\section{Interpretation of Results}

Our main results from the foregoing analysis are the following: Zipf's Law holds in the upper tail of the distributions of aggregate and high-skilled immigrant and emigrant levels, thereby demonstrating significant agglomeration in international mobility patterns. Gibrat's Law holds over most of the distribution of aggregate immigrant levels. Aggregate immigrant densities exhibit divergence; aggregate emigrant levels are converging and high-skilled immigrant and emigrant levels and densities all demonstrate patterns of convergence. The mechanisms that have been advocated in the urban economics literature as potential explanations for the emergence of the patterns described by Zipf's and Gibrat's laws, implicitly assume free mobility across space, which is clearly not appropriate in the case of international migration due to significant geographical, cultural and legal barriers to mobility. It is therefore difficult to argue that some natural law exists which determines the underlying growth and distribution processes of populations over national boundaries and across the globe. Since we do observe several stark patterns however, in this sub-section we discuss some of the potential mechanisms that might be driving the observed patterns.

Immigration patterns exhibit the strongest evidence of conforming to Zipf's law. Important migrant destinations, such as the United States, provide relatively open borders and economic opportunities for migrants. Conversely, less prominent destinations are likely to have neither. Those countries that attract the most significant numbers of immigrants tend to be wealthier more mature economies, which vie to attract high-skilled migrants in the global contest for talent, while concurrently requiring unskilled migrants to fill jobs in 'productivity growth resistant' service industries (Pritchett, 2006).

Particular pull and push factors play critical roles. In addition to differences in income levels between countries, we also observe that skilled workers earn higher incomes in absolute terms in wealthier countries. These observations may result in two of the prominent features of international migration patterns: positive migrant selection whereby more educated migrants move abroad with greater probabilities in comparison with their low skilled compatriots and migrant sorting whereby immigrants settle in greater 
numbers where skill premia are highest (Grogger and Hanson, 2011). These observations could explain why the United States and Canada receive more high skilled migrants in comparison with other countries.

Increasing numbers of destination countries are implementing selective migration policies, which favour migrants from countries with political and/or cultural ties or those with particular skills or professions. The ultimate roles of various immigration policies in establishing observed migratory patterns have not been fully established; more general immigration policies have been found to deter migrant flows (Mayda (2010), Ortega and Peri (2013)), but further work is needed to establish the extent to which selective migration policies affect high skilled migration flows. It is perhaps not a coincidence that many countries with selective immigration policies, such as Australia and Canada, also attract the greatest numbers of highly skilled immigrants. These observations go some way in explaining countries' locations in the total immigrant and high skilled immigrant distributions but cannot necessarily explain their relative ranking, one which adheres to Zipf's Law.

Formal emigration policy restrictions are less relevant than immigration policies since far fewer countries can implement them. Nevertheless, the world today contains fewer totalitarian regimes that at other times in history making it de facto easier for more people to move abroad. Between 1987 and 2005, the number of countries implementing emigration restrictions fell from 21 to just 11 (de Haas and Vezzoli, 2011). Regardless of explicit emigration policies, in many countries the costs of obtaining the required documentation, such as passports, are extremely high, which constitute de facto barriers to exit, typically in countries suffering from poor governance (McKenzie, 2007). With the advent of information technology and the increased provision of international travel, migration costs, including search, travel and the psychological costs of moving have been lowered for many. As a result we should (as indeed we do) observe increasing numbers of emigrants from an increasing number of origin countries globally.

Further compounding existing migration patterns are cultural, political and geographic bonds. Origin countries with strong ties to large destinations will have larger emigration 
levels - such as the case with Mexico and the United States or India and the United Kingdom. Further reinforcing such patterns is the role of migrant diasporas, since migrants are strongly attracted to destinations where other people from their villages, towns and countries settled in earlier periods. Network members can help new arrivals overcome legal and professional barriers and assimilate faster (Beine et al., 2011). To the extent that migration networks reduce migration costs, diasporas are likely to have a stronger effect on low skilled as opposed to high skilled workers (McKenzie and Rapoport, 2010), fostering overall immigrant flows, lowering the average education level, while increasing the concentration of low-skilled migrants (Beine et al., 2011). Migrant networks also affect the quality of migrants through their influence on individual's decision to invest in education however, which depend upon their prospect of migration. In this vein, (Bertoli and Rapoport, 2014) derive a theoretical model in which the adoption of skill selective immigration policies can result in network size being positively associated with migrant quality, a result that is entirely driven by endogenous investment decisions in education at origin.

The results from our exploration of Gibrat's Law are arguably of most interest, especially that Gibrat's Law holds over most of the distribution of aggregate immigrants. This finding alone warrants further academic enquiry. Secondly, emigration levels appear to be converging over time. Part of this trend is explained by countries such as Russia and Ukraine and those in South Asia, which appear in the upper tail of the distribution; between which many emigrants (recorded by country of birth) were created as a result of the dissolution of larger geographical entities.

Other countries in the upper tail include traditional countries of emigration for example Italy, Turkey, Spain, Mexico and Portugal, economies that have grown substantially over time, thereby lowering emigration pressures, an indication that they are located on the downward part of the migration transition curve (Clemens, 2014). Conversely, emigration rates are growing substantially for many of those countries in the lower tail of the distribution. These include many small island and poorer developing countries such that they would instead be located on the upward sloping part of the migration transition curve as their development spurs additional emigration. 
The distribution of immigrant densities is rather diverging. Nations in the upper tail include those Gulf states (Qatar, United Arab Emirates, Kuwait) that host larger numbers of immigrants in exchange for fewer workers' rights (Ruhs and Martin, 2008); as well as small advanced economies (Hong Kong, Singapore, Luxembourg) that continue to attract increasing amounts of foreign labour. For both groups, immigration rates clearly outstrip domestic fertility rates. The opposite holds true at the lower end of the distribution, since those countries are typically less attractive to migrants, often confronted by civil conflict (for examples Afghanistan, Iran, Egypt, Somalia and Nigeria), have far higher fertility rates and indeed constitute more traditional countries of emigration.

Our exploration of Gibrat's Law for highly skilled migrants indicates that across the world, high skilled immigrant and emigrant distributions in levels and densities all exhibit signs of convergence. Beginning with immigrant levels, non-traditional destinations' increasing popularity is no doubt in part driven by a growing recognition of the need to attract human capital in tandem with rising wages and skill premia in those countries.

In terms of immigration densities, convergence could result from a) the role of networks (in terms of their generally attracting lower skilled workers) dominating the effects of migrant sorting, selective immigration policies and forces of agglomeration - such as increasing returns to concentrations of high skilled workers - in the upper tail of the distribution and b) the endogeneity of migration and fertility, (where for example successful migration spurs higher birth rates) and the proliferation of selective immigration policies in the lower tail of the distribution.

Convergence in emigration levels is consistent with destinations continuing to attract human capital from an increasing number of migrant origins. The upper tail of the distribution contains several countries for which mobility has long been a possibility, for example the UK, Germany, Canada and the USA, and so many that had the desire to leave would already have left. Converging emigration densities indicates an increasing negative selection from countries that send the greatest proportions of highly skilled abroad. This could be driven by the establishment of larger migrant networks, lower migration costs, or lower absolute skill-related differences in origin-destination earnings. 


\section{Conclusion}

Gibrat's and Zipf's laws are among the most studied and well established phenomena in various contexts including linguistics, firm sizes and urban agglomorations. The linkages between population growth and the distribution across geographic space are key to all economic analysis since economic activity cannot be analyzed in isolation from location. It is therefore important to study and identify the underlying processes that determine the growth rates of populations over time and their allocation across various locations. Even though Zipf's and Gibrat's laws have been extensively analyzed in the literature, there are few such studies on the role of population movements across national boundaries. It is therefore natural to search for a relationship between such population laws and migration patterns.

With regards Zipf's law, we see migration patterns that are similar to what is observed with respect to cities. In the upper end of the distribution, Zipf's law holds since the Pareto coefficient is very close to unity. High-skilled levels satisfy (although less well) Zipf's Law. Examinations of Gibrat's law rather require dynamic analysis. We find evidence of convergence in our parametric analysis and evidence in favour of Gibrat's Law holding for immigration stocks in our non-parametric analysis. Conversely, emigrant stocks are converging in the sense that countries with smaller emigrant stocks are growing faster than their larger sovereign counterparts.

In this paper we extend insights from the urban economics literature to international migration. Zipf's and Gibrat's laws provide natural avenues to do so since they are linked via population movements. We find various support for these laws in international migration which is surprising given the policies and many other barriers that limit international migration patterns. 


\section{References}

Artuç, E., F. Docquier, CaĞlar Özden, and C. Parsons" (2014): “A Global Assessment of Human Capital Mobility: The Role of Non-OECD Destinations," World Development, - .

Beine, M., F. Docquier, And C. Özden (2011): "Diasporas," Journal of Development Economics, 95, 30-41.

Bertoli, S. And H. Rapoport (2014): "Heaven's Swing Door: Endogenous Skills, Migration Networks, and the Effectiveness of Quality-Selective Immigration Policies," The Scandinavian Journal of Economics, online early release.

Clemens, M. (2014): "Does Development Reduce Migration?" CGD Working Paper WP-359, Washington, DC: Center for Global Development.

Clemente, J., R. González-Val, And I. Olloqui (2011): "Zipfs and Gibrats laws for migrations," The Annals of Regional Science, 47, 235-248.

DE HaAs, H. AND S. Vezzoli (2011): "Leaving matters: the nature, evolution and effects of emigration policies," IMI Working Paper WP-34-2011, University of Oxford, International Migration Institute.

De la Croix, D., F. Docquier, And M. Schiff (2013): "Brain Drain and Economic Performance in Small Island Developing States," in The Socio-Economic Impact of Migration flows. Effects on Trade, Remittances, Output, and the Labour Markets, ed. by G. P. Andrés Artal-Tur and F. Requena-Silvente, Springer, chap. 6.

Eaton, J. And Z. Eckstein (1997): "Cities and growth: Theory and evidence from France and Japan," Regional Science and Urban Economics, 27, 443-474.

Eeckhout, J. (2004): "Gibrat's Law for (All) Cities," American Economic Review, 94, $1429-1451$.

Gabaix, X. (1999): "Zipf's Law for Cities: An Explanation," The Quarterly Journal of Economics, 114, 739-767. 
Gabaix, X. And R. Ibragimov (2007): "Rank-1/2: A Simple Way to Improve the OLS Estimation of Tail Exponents," NBER Technical Working Papers 0342, National Bureau of Economic Research, Inc.

Gabaix, X. And Y. M. IoAnnides (2004): "The evolution of city size distributions," in Handbook of Regional and Urban Economics, ed. by J. V. Henderson and J. F. Thisse, Elsevier, vol. 4 of Handbook of Regional and Urban Economics, chap. 53, 2341-2378.

Gibrat, R. (1931): Les inégalités économiques: applications: aux inégalités des richesses ... aux statistiques des familles, etc. d'une loi nouvelle, la loi de l'effet proportionnel, Librairie du Recueil Sirey.

González-VAl, R. And M. Sanso-Navarro (2010): "Gibrats law for countries," Journal of Population Economics, 23, 1371-1389.

Grogger, J. And G. H. Hanson (2011): "Income maximization and the selection and sorting of international migrants," Journal of Development Economics, 95, 42-57.

MAYDA, A. (2010): "International migration: a panel data analysis of the determinants of bilateral flows," Journal of Population Economics, 23, 1249-1274.

McKenzie, D. (2007): "Paper Walls Are Easier to Tear Down: Passport Costs and Legal Barriers to Emigration," World Development, 35, 2026-2039.

McKenzie, D. And H. Rapoport (2010): "Self-Selection Patterns in Mexico-U.S. Migration: The Role of Migration Networks," The Review of Economics and Statistics, $92,811-821$.

Ortega, F. And G. Peri (2013): "The effect of income and immigration policies on international migration," Migration Studies, 1, 47-74.

Özden, C., C. R. Parsons, M. Schiff, and T. L. Walmsley (2011): "Where on Earth is Everybody? The Evolution of Global Bilateral Migration 1960-2000," The World Bank Economic Review. 
PRITCHETT, L. (2006): Let their people come: breaking the gridlock on international labor mobility, G - Reference, Information and Interdisciplinary Subjects Series, Center for Global Development.

Rose, A. K. (2005): "Cities and Countries," NBER Working Papers 11762, National Bureau of Economic Research, Inc.

Ruhs, M. And P. Martin (2008): "Numbers vs. Rights: Trade-Offs and Guest Worker Programs1," International Migration Review, 42, 249-265. 
Figure 1: Kernel Density Plots Aggregate Immigrants and emigrants levels and densities, 1960-2000
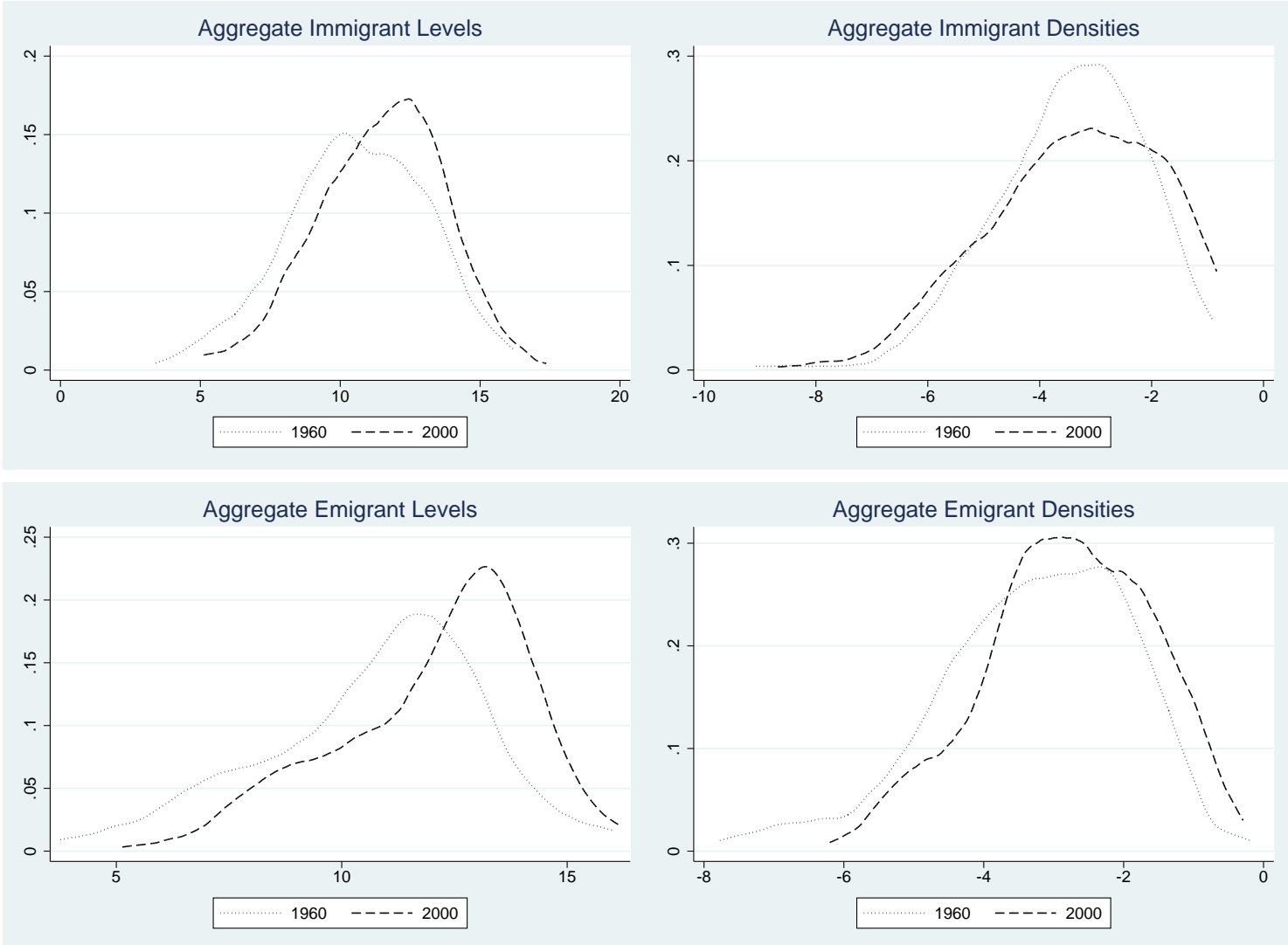
Figure 2: Graphical Examination of Gibrat's Law across Bilateral Corridors, 1960-2000

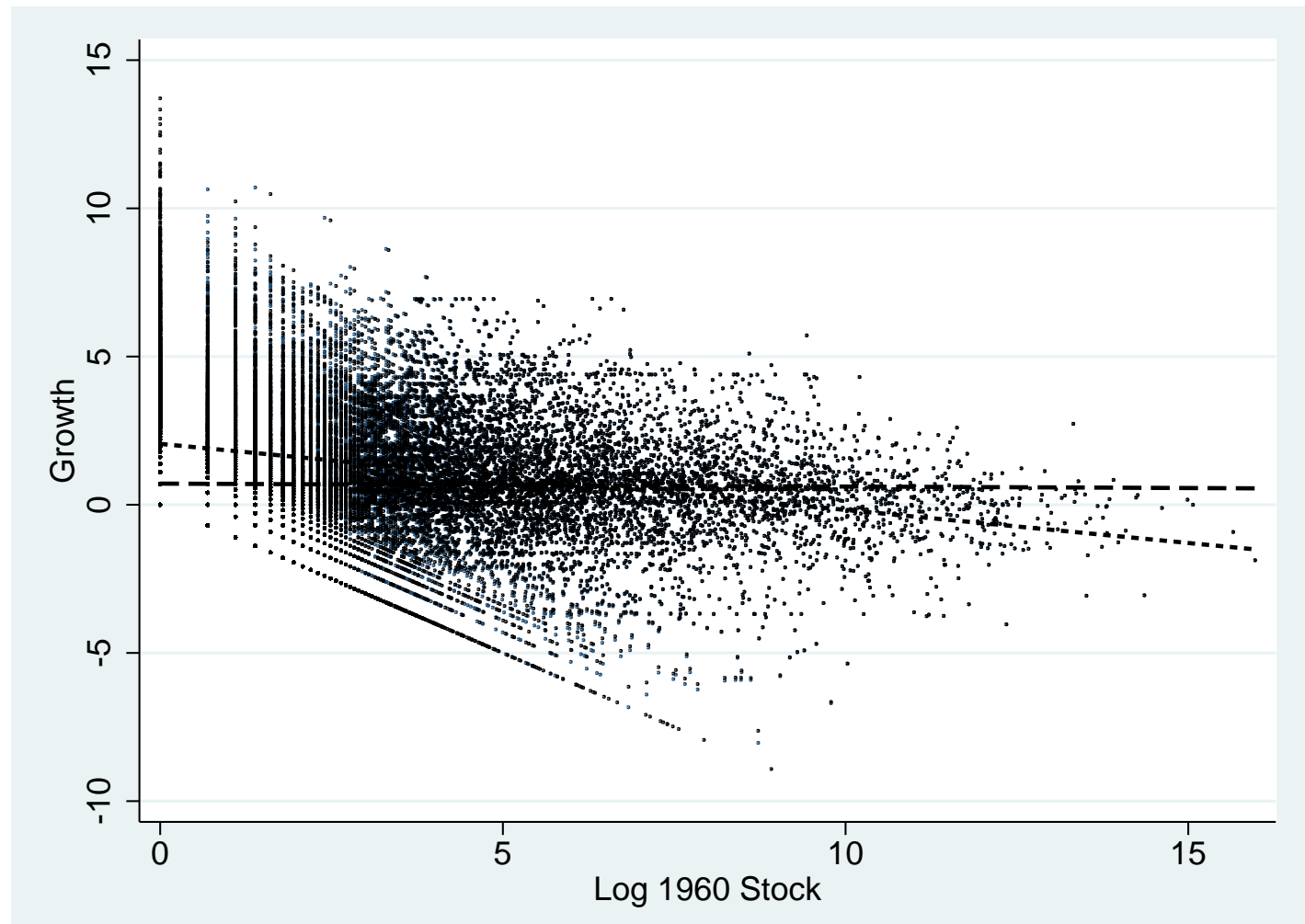


Figure 3: Zipf Plots for Aggregate and High-skilled Immigrants and Emigrants, 2000
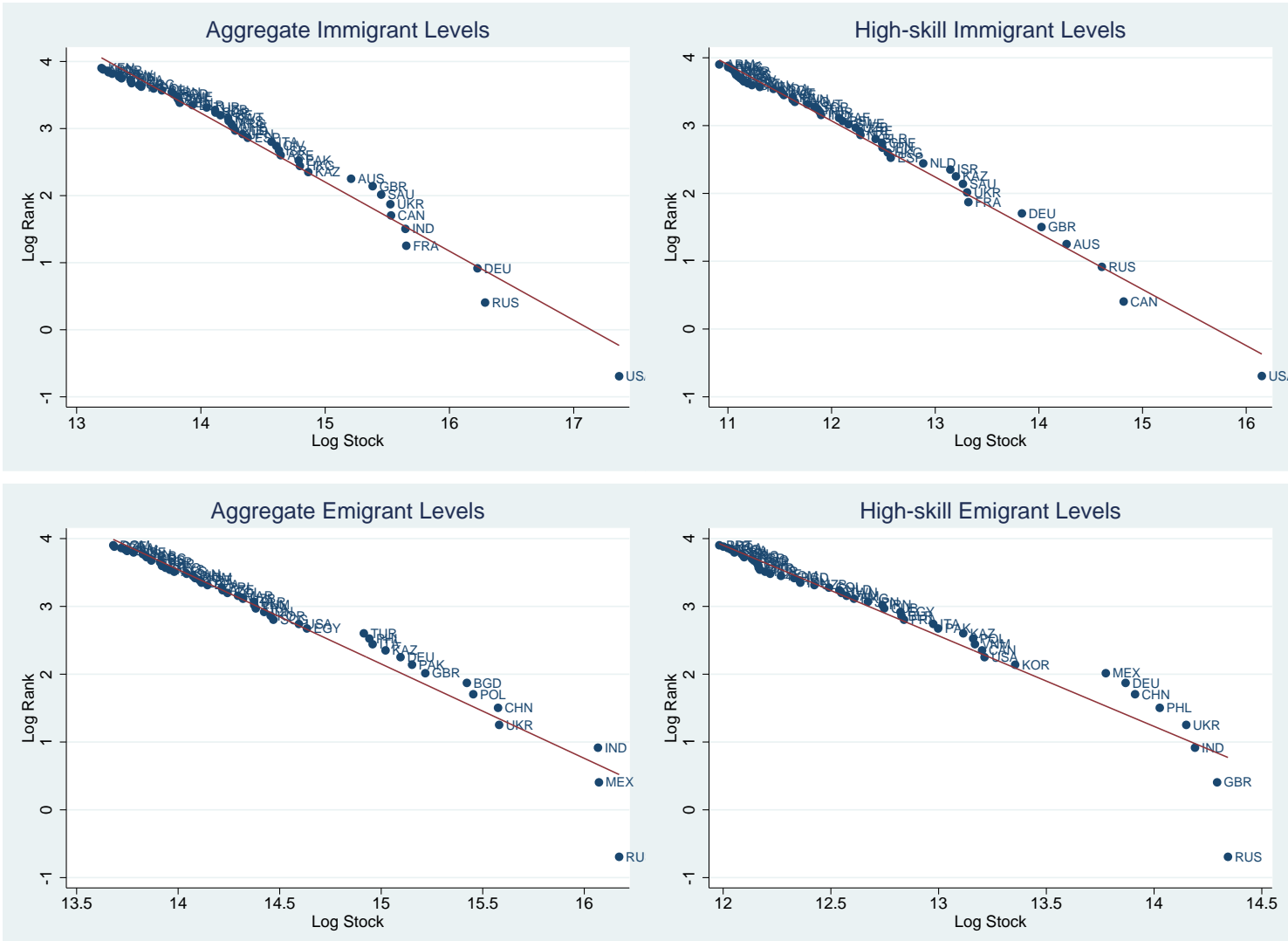
Figure 4: Kernel Density Plots High-Skilled Immigrants and emigrants levels and densities, 1990-2000
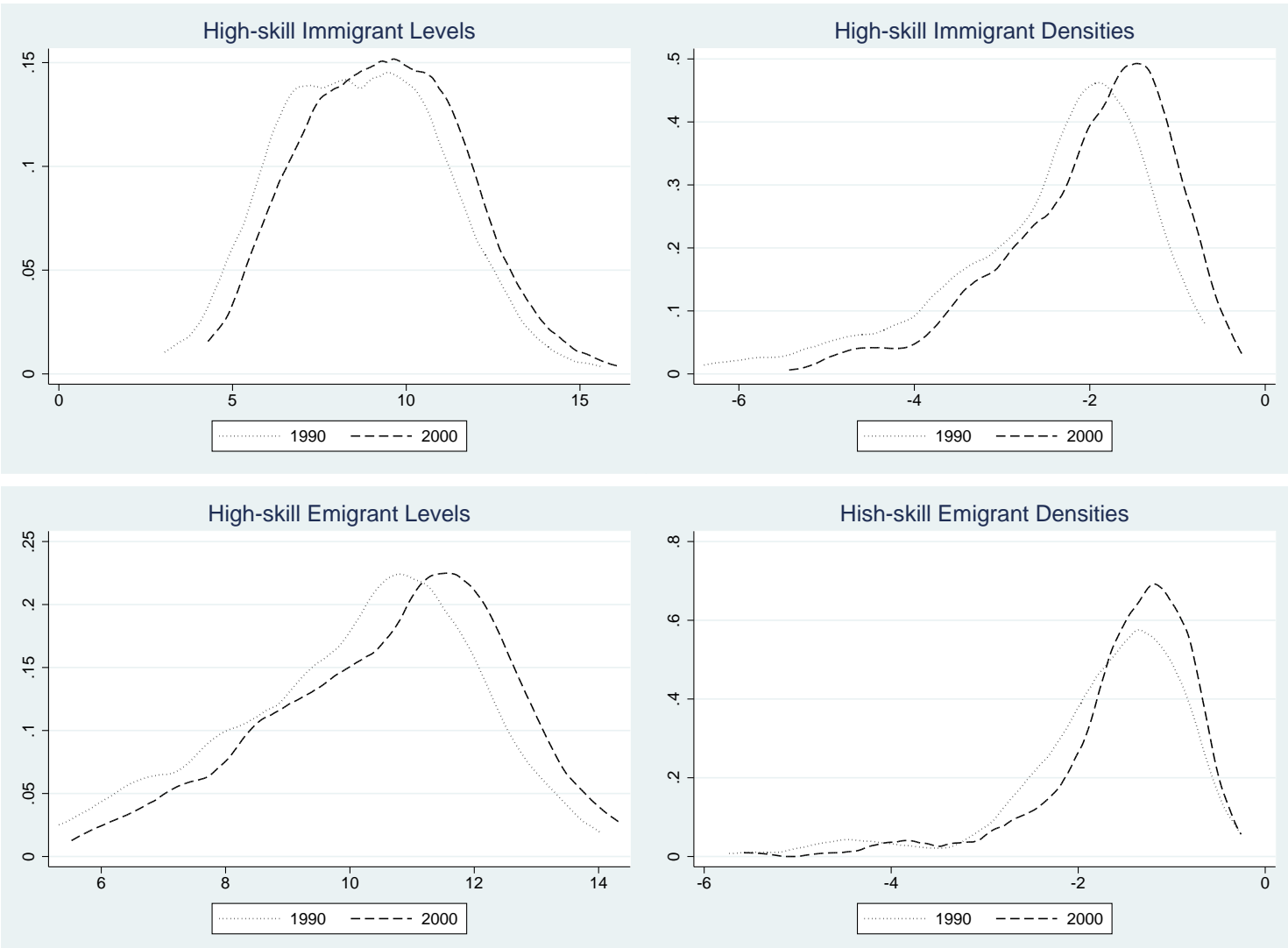
Figure 5: Non-parametric estimation of Gibrat's Law, aggregate immigrant and emigrant levels and densities, 1960-2000
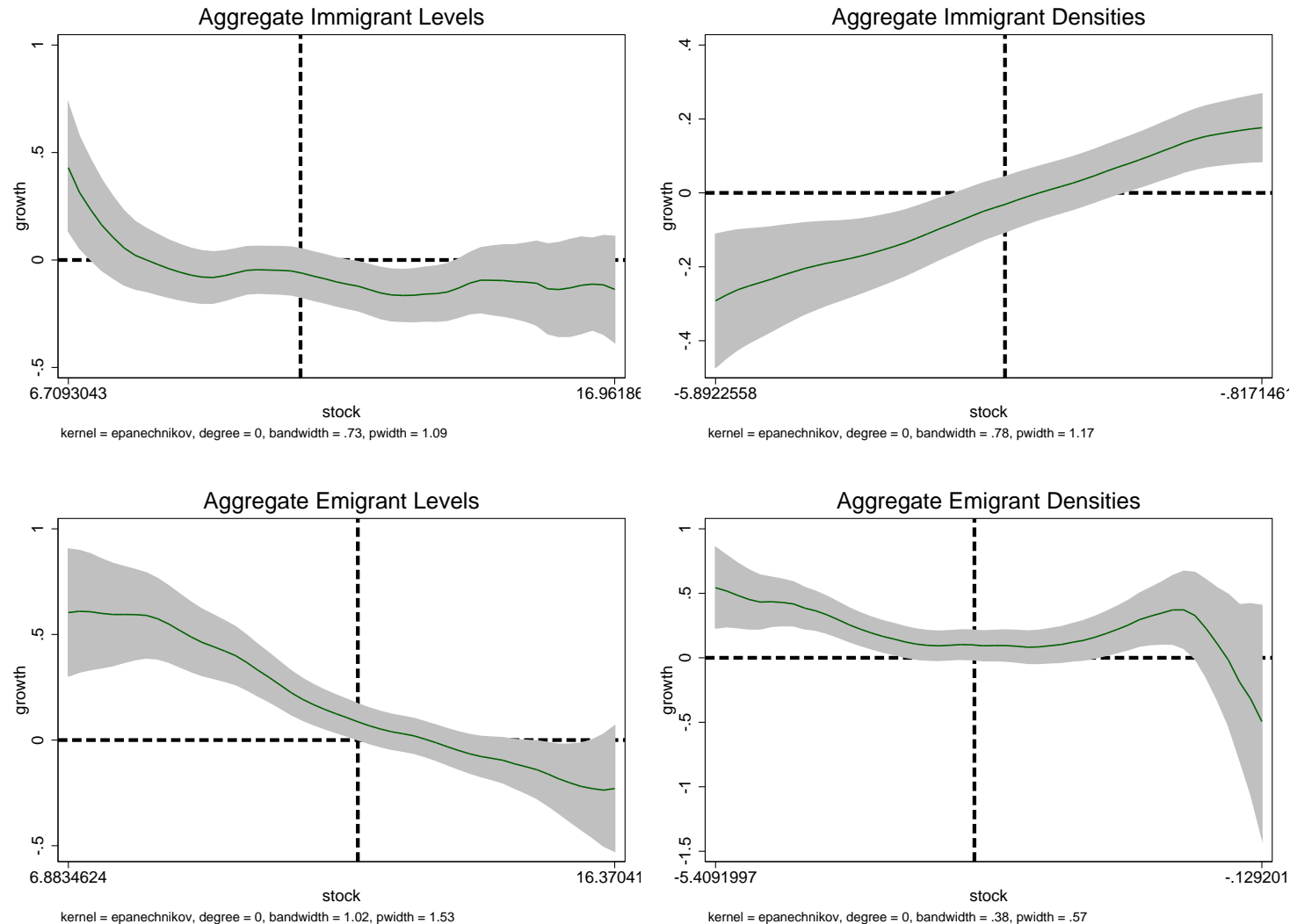
Figure 6: Non-parametric estimation of Gibrat's Law, high-skilled immigrant and emigrant levels and densities, 1990-2000
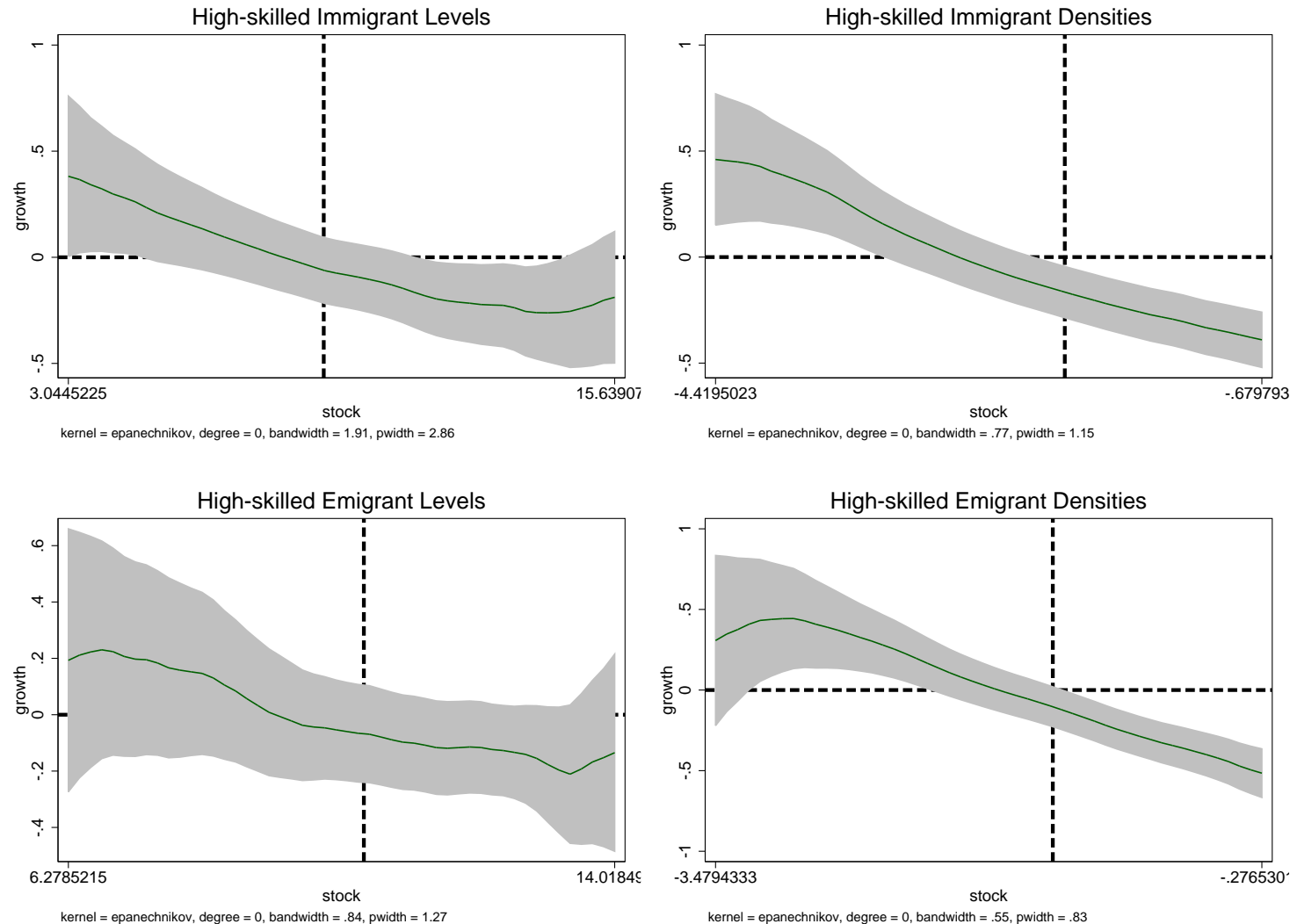


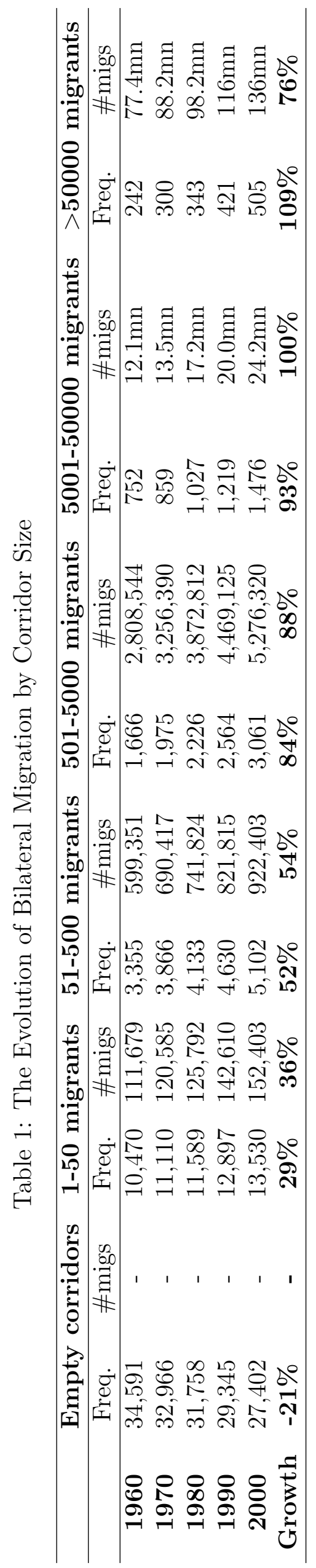




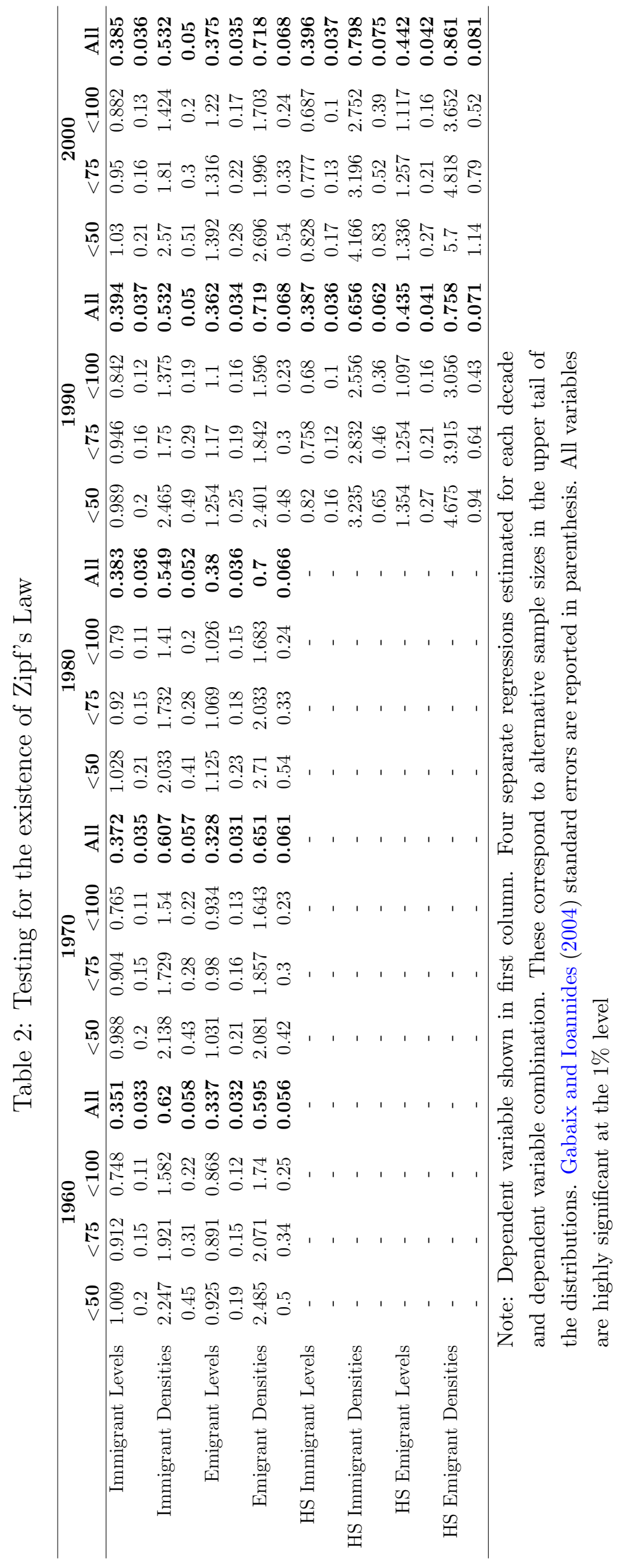


Table 3: P-values from Kolmogorov-Smirnov equality-of-distributions tests

\begin{tabular}{rcc}
\hline & $\mathbf{1 9 6 0}$ or $\mathbf{1 9 9 0} \mathbf{p}$-values & $\mathbf{2 0 0 0} \mathbf{~ p - v a l u e s}$ \\
\hline Immigrant Levels & 0.791 & 0.591 \\
Immigrant Densities & 0.427 & 0.469 \\
Emigrant Levels & $\mathbf{0 . 0 3 3}$ & $\mathbf{0 . 0 0 1}$ \\
Emigrant Densities & 0.267 & 0.578 \\
HS Immigrant Levels & 0.426 & 0.86 \\
HS Immigrant Densities & $\mathbf{0 . 0 0 1}$ & $\mathbf{0 . 0 0 3}$ \\
HS Emigrant Levels & $\mathbf{0 . 0 6 4}$ & 0.14 \\
HS Emigrant Densities & $\mathbf{0 . 0 0 2}$ & $\mathbf{0 . 0 0 1}$ \\
\hline
\end{tabular}


Table 4: Parametric Tests of Gibrat's Law

\begin{tabular}{rccccc}
\hline & $\mathbf{1 9 6 0 - 1 9 7 0}$ & $\mathbf{1 9 7 0 - 1 9 8 0}$ & $\mathbf{1 9 8 0 - 1 9 9 0}$ & $\mathbf{1 9 9 0 - 2 0 0 0}$ & $\mathbf{1 9 6 0 - 2 0 0 0}$ \\
\hline Immigrant Levels & $-0.0715^{* * *}$ & $-0.0570^{* * *}$ & $-0.0569^{* * *}$ & -0.0154 & $-0.234^{* * *}$ \\
& $(0.0144)$ & $(0.0132)$ & $(0.0146)$ & $(0.0141)$ & $(0.0323)$ \\
Immigrant Densities & -0.0349 & 0.014 & -0.0318 & $-0.0480^{*}$ & $-0.241^{* * *}$ \\
& $(0.0222)$ & $(0.0295)$ & $(0.0258)$ & $(0.0275)$ & $(0.0555)$ \\
Emigrant Levels & -0.0215 & $-0.171^{* * *}$ & -0.0185 & $-0.0695^{* * *}$ & $-0.221^{* * *}$ \\
& $(0.0174)$ & $(0.0259)$ & $(0.0259)$ & $(0.0217)$ & $(0.0241)$ \\
Emigrant Densities & $-0.132^{* * *}$ & $-0.236^{* * *}$ & $-0.127^{* * *}$ & $-0.0782^{* *}$ & $-0.384^{* * *}$ \\
& $(0.0239)$ & $(0.0427)$ & $(0.0383)$ & $(0.0342)$ & $(0.0392)$ \\
HS Immigrant Levels & - & - & - & $-0.0735^{* * *}$ & - \\
HS Immigrant Densities & - & - & - & $(0.0201)$ & - \\
HS Emigrant Levels & - & - & - & $-0.275^{* * *}$ & - \\
& - & - & - & $(0.0566)$ & - \\
HS Emigrant Densities & - & - & - & $-0.0352^{* *}$ & - \\
& - & - & - & $-0.186^{* * *}$ & - \\
\hline
\end{tabular}

Note: Dependent variables shown in first column. Robust standard errors are reported in parenthesis. ${ }^{* * *} \mathrm{p}<0.01,{ }^{* *} \mathrm{p}<0.05,{ }^{*} \mathrm{p}<0.1$. 